\title{
OCORRÊNCIA DE CAULINITA NO ESPINHAÇO, MG
}

G.N.C.Sgarbi ${ }^{1}$

A.H.Horn ${ }^{2}$

\section{RESUMO}

O presente trabalho investiga um corpo magmático intrusivo, caulinizado, que ocorre perto de Diamantina nos Grupos Espinhaģo (Proterozóico Médio) e Rio Paraúna (Proterozoico Inferior?). Dados mineralógicos obtidos por difratometria de raios X (DRX), químicos por fluorescência de raios X (FRX), morfológicos por microscopia eletrônica de varredura (MEV) e análise de capacidade de troca catiônica (CTC) indicam que esta ocorrência é constituída em grande parte por caulinita de alta cristalinidade, não expansiva e quimicamente pura. Estes estudos, aliados a observaçóes de campo, sugerem, para esta ocorrência mineral, uma origem autigênica, comandada pela precipitaçāo direta a partir de fluidos meteóricos, originários da alteraçâo de minerais alumino-silicáticos presentes originalmente na rocha.

\section{ABSTRACT}

A kaolinized intrusive body occurring in Precambrian rocks of the Espinhaço (Middle Proterozoic) and Rio Paraúna (Upper Proterozoic?) Groups in the Diamantina region was studied. X-ray diffractometry (XRD), X-ray fluorescence (XRF), scanning electron microscopy (SEM) and cation exchange capacity (CEC) data have shown that this kaolinite is a well crystallized, non-expansive, chemically pure clay mineral. These studies, together with field observations, suggest that the kaolinite originated by direct precipitation from subsurface solutions deriving from weathering alteration of the aluminosilicate minerals of the basic intrusive rock.

\footnotetext{
${ }_{1}^{1}$ Departamento de Geologia, Instituto de Geociências, Universidade Federal de Minas Gerais.

${ }^{2}$ Centro de Pesquisa Prof.Manoel Teixeira da Costa, Instituto de Geociências, Universidade Federal de Minas Gerais.
} 


\section{TRABALHOS PRÉVIOS}

As primeiras referências petrológicas sobre metabasitos intrusivos no Supergrupo Espinhaço e seqüências mais antigas deve-se a GUIMARÃES (1933). GROSSI SAD \& VAZ DE MELO (1969) descreveram a evolução intempérica destes metabasitos, a qual originou acumulaçóes importantes de bauxita na região. SCHÖLL \& FOGAÇA (1981) descreveram diques e soleiras de dioritos, gabros e diabásios, incipientemente metamorfizados, os quais geraram, por intemperismo, ocorrências localizadas de caulim, mencionando especificamente o corpo caulinítico ora investigado. UHLEIN (1982) apresentando uma compilaçăo sobre a ocorrência de metabásicas no Espinhaço Meridional, destaca a ocorrência de bauxita, relacionada com a alteração intempérica destes corpos intrusivos.

\section{MÉTODOS DE INVESTIGAÇÃo}

Além da execução de trabalhos de campo, os quais permitiram a delimitação do corpo intrusivo ora investigado, as caulinitas foram analisadas por DRX (rocha total e fraçăo argila) utilizando um difratômetro RIGAKU/RV 200, com radiaçăo CuK $\alpha$ e os dados químicos de FRX foram obtidos por meio de um aparelho RIGAKU A. Na investigação por MEV utilizou-se um microscópio JEOL-JXA/800 A, equipado com sistema de análises por energia dispersiva de raios $\mathrm{X}$ (EDX). As análises de capacidade de troca catiônica foram realizadas segundo o método descrito por HILL (1982 apud KHALIL \& TEIXEIRA, 1990).

\section{CONDICIONAMENTO GEOLÓGICO}

O corpo caulinizado ora investigado ocorre a oeste do km 116 da BR-367 (Curvelo-Diamantina), na forma de um dique que corta unidades proterozóicas representadas pelos Grupos Rio Paraúna e Espinhaço, ambos predominantemente quartzíticos. Ele estendese por cerca de $500 \mathrm{~m}$ na direçăo aproximadamente leste-oeste, subparalelamente a uma falha indiscriminada situada a sul, com espessuras que variam entre 5 e $20 \mathrm{~m}$, sendo cortado transversalmente por fraturas cujos planos encontram-se às vezes enriquecidos em sericita e quartzo. Seus limites a oeste e leste são representados por falhas de empurrão sendo recobertos a leste por material coluvionar (Fig. 1).

O dique possui direção $N 75^{\circ} \mathrm{W}$ e mergulho subvertical. Para efeitos de estudo o mesmo foi subdividido em dois corpos ( $\mathrm{I}=$ oeste; $I I=$ leste), exibindo, ambos, zoneamento subparalelo à sua maior dimensão. Sondagens a trado mostraram a continuidade do caulim sob o material coluvionar situado entre os dois corpos, o qual, com espessuras variando entre 0,5 e 0,6 m é constituído por areia argilosa preta, com acréscimo de material orgânico do topo para a base. O contato entre o colívio e o caulim é gradacional, com 

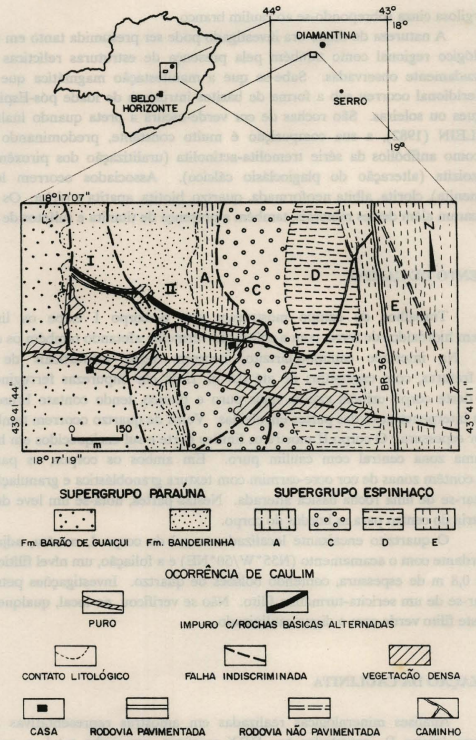

Figura 1 - Mapas de localizaçāo e geológico (nomenclatura segundo SCHÖLL \& FOGAÇA, 1981) da área de ocorrencia do corpo caulinizado investigado. 
uma fração argilosa cinza sobrepondo-se ao caulim branco.

A natureza do dique ora investigado pode ser presumida tanto em função do contexto geológico regional como também pela presença de estruturas relícticas da rocha básica, localizadamente observadas. Sabe-se que a manifestação magmática que afetou o Espinhaço Meridional ocorreu sob a forma de basitos intrusivos de idade pós-Espinhaço, na forma de diques ou soleiras. São rochas de cor verde-escura a preta quando inalteradas e, segundo UHLEIN (1982), a sua composição é muito constante, predominando minerais secundários como anfibólios da série tremolita-actinolita (uralitizaçấo dos piroxênios) e de epidoto-clinozoizita (alteração do plagioclásio cálcico). Associados ocorrem leucoxênio (núcleo de ilmenita), clorita, albita neoformada, quartzo, biotita, apatita e pirita. Os presentes autores verificaram além destes minerais, também a presença de titanita e sulfetos de cobre.

\section{DETALHAMENTO DE CAMPO}

Trabalhos de campo mostraram que o corpo I exibe os limites sul enriquecidos em hidróxidos de ferro, com a coloração vermelha afetando também os quartzitos encaixantes. $\mathrm{Na}$ interface caulim-quartzito, ocorrem veios subverticais de quartzo, preenchendo fraturas, com espessuras de até $0,5 \mathrm{~m}$, ricos em impurezas ferruginosas. Os limites norte deste corpo exibem caulim mais puro e branco, tendo contato brusco com o quartzito, sem interpenetraçáo das partes envolvidas. Veios de quartzo ocorrem também aqui, mas em menor espessura. O corpo II mostra os limites norte e sul enriquecidos em hidróxidos de ferro e uma zona central com caulim puro. Em ambos os corpos, as partes mais avermelhadas contêm zonas de cor ocre-carmim com textura granoblástica e granulação média, sugerindo tratar-se de uma rocha básica alterada. Nestas partes, nota-se um leve decréscimo da granulometria do centro para as bordas do corpo.

O quartzito encaixante localizado ao sul do corpo I, mostra, adjacente ao dique e concordante com o acamamento $\left(\mathrm{N}^{\circ} 5^{\circ} \mathrm{W} / 50^{\circ} \mathrm{NE}\right.$ ) e a foliação, um nível filítico (verde) com cerca de $0,8 \mathrm{~m}$ de espessura, contendo bolsões de quartzo. Investigaçóes petrograficas mostram tratar-se de um sericita-turmalina filito. Não se verificou, no local, qualquer relação inequívoca deste filito verde com o dique caulinizado.

\section{CARACTERIZAÇÃo DA CAULINITA}

Análises mineralogicas realizadas em amostras representativas do corpo caulinizado puro (corpo I), executadas por DRX mostram, em rocha total, a presença de quartzo e caulinita (Fig. 2). Dosagem da sílica livre cristalizada, realizada também por DRX indica $8 \%$ de quartzo e $92 \%$ de caulinita. A fraçăo argila $(<0,002 \mathrm{~mm}$ ) mostra, pelo mesmo método, $100 \%$ de caulinita de alta cristalinidade, fato evidenciado pelos picos bem formados 
dos difratogramas (Fig. 3).

Confirmando os dados difratométricos, a investigação por MEV na fração argila do corpo caulinizado (ANJOS et al, 1991), mostra a presença de agregados de placas euédricas de caulinita, associados a flocos de caulinita anédrica. A composição química qualitativa, determinada por EDX indicou unicamente a presença de silica e alumínio, tanto nos agregados como nos flocos de caulinita. Nesta fraçâo argila, nem quartzo nem sericita, localmente presentes em rocha total, foram observados. Aspectos morfológicos do corpo caulinizado em questão encontram-se ilustrados a seguir (Estampa 1).

Análise de capacidade de troca catiônica (CTC), objetivando determinar a concentração de cátions intercambiáveis desta caulinita mostra um valor extremamente baixo $(0,99 \mathrm{meq} / 100 \mathrm{~g})$, o qual indica, além de nítida correlaçăo com o teor de caulinita determinada por DRX, o caráter puro deste argilomineral. Teores adicionais de esmectita, illita ou interestratificado illita-esmectita, elevariam significativamente o valor da CTC encontrado. Para fins instrutivos săo comparados valores da CTC da caulinita do Espinhaço com outros provenientes de várias outras argilas (Tabela 1). Os dados mostram que uma classificação genérica das amostras analisadas quanto aos seus cátions intercambiáveis, permitem agrupar as amostras 1,2 e 3 como argilas empobrecidas em $\mathrm{Na}^{+} \mathrm{e} \mathrm{Ca}^{++}$, com baixos valores de CTC e, conseqüentemente, não expansivas. As amostras 4 e 5 , de natureza sódio-cálcica e elevados teores em CTC, foram classificados por KHALIL \& TEIXEIRA (1990) como argilas expansivas. A argila 6, de natureza cálcica, foi também classificada por estes autores como medianamente expansiva e com média capacidade de troca catiônica.

Análises químicas por FRX confirmaram a alta pureza química da caulinita ora investigada, com sílica e alumínio totalizando $97,7 \%$ em peso da rocha seca (Tabela 2 ).

\section{ORIGEM DA CAULINITA}

Caulinitas autigênicas podem formar-se, segundo BLATT (1985), por dois processos distintos:

a. por precipitaçăo direta a partir de soluçōes supersaturadas, gerando agregados predominantemente euédricos que ocupam a porosidade disponível da rocha (equação 1).

b. por alteraçáo in situ de feldspatos e de outros minerais alumino-silicáticos, neste caso formando cristais anédricos (equação 2).

$$
2 \mathrm{Al}(\mathrm{OH})_{3}+\underset{\text { caulinita }}{2 \mathrm{H}_{4} \mathrm{SiO}_{4}}+\underset{\mathrm{Al}_{2} \mathrm{Si}_{2} \mathrm{O}_{5}(\mathrm{OH})_{4}}{\mathrm{AH}_{2} \mathrm{O}}
$$

$2 \mathrm{KAlSi}_{3} \mathrm{O}_{8}+2 \mathrm{H}^{+}+9 \mathrm{H}_{2} \mathrm{O} \rightarrow \mathrm{Al}_{2} \mathrm{Si}_{2} \mathrm{O}_{5}(\mathrm{OH})_{4}+2 \mathrm{~K}^{+}+4 \mathrm{H}_{4} \mathrm{SiO}_{4}$ 


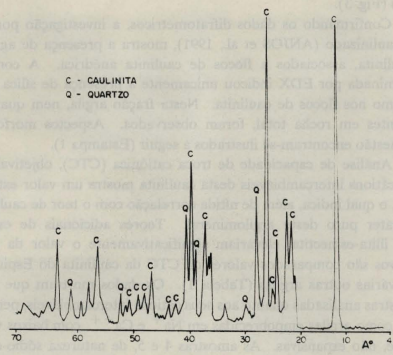

Figura 2 - Padrão suavizado de difratograma natural (p6) de caulim, mostrando caulinita e quartzo.

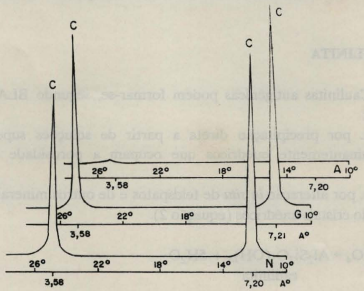

Figura 3 - Padrão suavizado de difratograma natural (N), glicolado (G) e aquecido (A), da fraçăo inferior a 0,002 mm de caulim, mostrando unicamente caulinita de alta cristalinidade. 

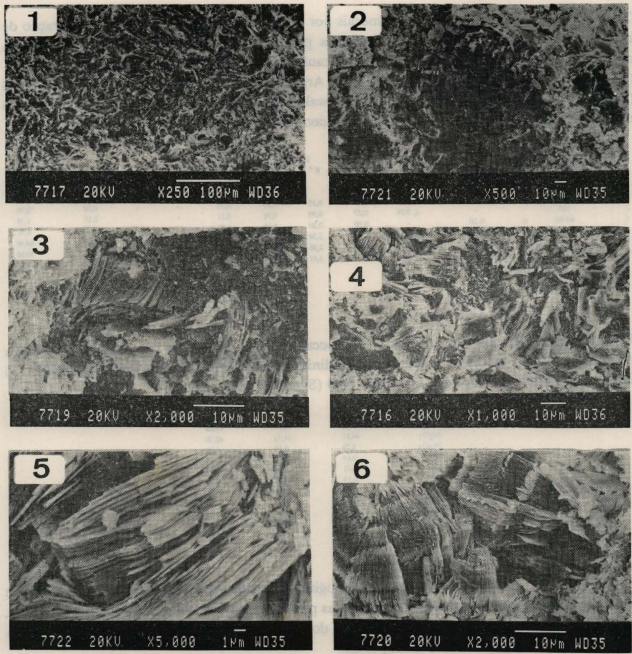

Estampa 1 - Fotomicrografias por MEV mostrando:

1. Aspecto geral da fraçẩo argila revelando intensa caulinização a partir de minerais alumino-silicáticos, com zonas mais ricas em cristais euedricos circundados por uma massa de caulinita anédrica (aumento de $250 x$ ).

2. Detalhe de área preenchida por caulinita euédrica circundada por caulinita anédrica (aumento de $500 \mathrm{x}$ ).

3. Caulinitas autigenicas predominando sob a forma de "books" (aumento de $1000 x$ ).

4. Detalhe de caulinitas cristalizadas sob a forma de "books" (aumento de 2000x).

5. Detalhe de agregados de placas euédricas de caulinita (aumento de $5000 x$ ).

6. Detalhe de caulinita vermicular presente na foto 2 (aumento de $2000 \mathrm{x}$ ). 
Tabela 1 - I: Mineralogia de argilominerais por DRX; II: Especificação da concentração de cátions intercambiáveis, em mili-equivalentes por $100 \mathrm{~g}$ de amostra; III: Valor total da capacidade de troca catiônica $($ CTC). $\mathrm{Cau}=$ caulinita; III = illita; Esm = esmectita.

(1) Caulinita da Serra do Espinhaço; (2) Argilas da bacia eocênica do Gandarela, MG (SGARBI et al., 1991); (3) Caulinita de Cornwall, U.K. (WORTHINGTON et al., 1979); (4, 5 e 6) Argilas da bacia do Recôncavo, BA, Cretáceo Inferior (KHALIL \& TEIXEIRA, 1990).

\begin{tabular}{|c|c|c|c|c|c|c|c|c|c|c|c|}
\hline \multicolumn{3}{|c|}{$\begin{array}{l}\text { 1- TEOR \% DRX } \\
\text { Fr }<0,002 \mathrm{~mm}\end{array}$} & \multirow[b]{2}{*}{$\mathbf{u}^{*}$} & \multirow[b]{2}{*}{$\mathrm{Na}^{+}$} & \multicolumn{3}{|c|}{ II-TEOR (moq/100 g) } & \multirow[b]{2}{*}{$\mathrm{Sr}^{++}$} & \multirow[b]{2}{*}{$\mathrm{H}^{+}$} & \multirow[b]{2}{*}{$\begin{array}{c}\mathrm{Ca}^{++} / \mathrm{Na}^{*} \\
(\mathrm{meq} / \mathrm{meq})\end{array}$} & \multirow[b]{2}{*}{$\begin{array}{c}\text { CII } \\
\text { meq } / 100 \mathrm{~g}\end{array}$} \\
\hline CAU & $\begin{array}{l}\text { WL/ESM } \\
\text { (IS) }\end{array}$ & $\begin{array}{l}\text { III/EM } \\
\text { (IS) }\end{array}$ & & & $\mathrm{K}^{+}$ & $\mathrm{Mg}^{++}$ & $\mathrm{Ca}^{+++}$ & & & & \\
\hline 100 & . & . & $\leqslant 0,04$ & 0,63 & 0,12 & 0.08 & 0.19 & . & . & 0,30 & 0.99 \\
\hline 100 & - & . & $\leqslant 0,04$ & 0,27 & 0.90 & 0.31 & 0.31 & . & . & 1,15 & $1, \pi$ \\
\hline \multirow[t]{2}{*}{$85-90$} & tr. & $8-10$ & 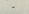 & 0,20 & 020 & 0.80 & 1,20 & . & 3,00 & 6,00 & 4,90 \\
\hline & 100 & $15-20$ & 0,07 & 21,57 & 5,50 & 6,74 & 2,71 & 0,40 . & 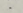 & 1,38 & 64,00 \\
\hline \multirow[t]{2}{*}{10} & 90 & $5-20$ & $a 02$ & 30,8 & 2,38 & 6,94 & 4200 & 0,62 & 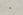 & 1,36 & 83,00 \\
\hline & 100 & $25-30$ & 0,13 & 0,59 & 1,41 & 4,98 & 3780 & 0,17 & . & 64,00 & 45,10 \\
\hline
\end{tabular}

Tabela 2 - Análises químicas por FRX, base seca, fraçāo < 0,002 mm. (1) Caulinita da Serra do Espinhaço; (2) Média de 5 análises de caulinita de Cornwall, U.K. (JASMUND, 1979); (3) Caulinita da bacia eocênica do Gandarela, MG (SGARBI et al., 1991).

$\begin{array}{llll} & 1(\xi) & 2(5) & 3(\%) \\ \mathrm{SiO}_{2} & 53,20 & 52,56 & 47,80 \\ \mathrm{~N}_{2} \mathrm{O}_{3} & 44,51 & 44,42 & 40,10 \\ \mathrm{Fe}_{2} \mathrm{O}_{3} & 0,70 & 0,59 & 3,31 \\ \mathrm{~K}_{2} \mathrm{O} & 0,69 & 1,44 & 3,01 \\ \mathrm{M} \mathrm{O}_{6} \mathrm{O} & 0,41 & 0,14 & 0,05 \\ \mathrm{CaO} & 0,19 & 0,26 & \\ \mathrm{THO}_{2} & 0,12 & 0,04 & 4,78 \\ \mathrm{P}_{2} \mathrm{O}_{5} & 0,04 & 0,04 \\ \mathrm{Na}_{2} \mathrm{O} & 0,01 & 0,04 & \\ \text { TOTAL } & 99,95 & 99,29 & 99,86\end{array}$

No presente caso, as morfologias observadas por MEV (Estampa 1) mostram zonas ricas em caulinitas euédricas, circundadas por uma massa flocular de caulinitas anédricas, associaçăo que sugere a atuação conjunta dos dois processos genéticos acima descritos, porém em um contexto eminentimente intempérico.

Um outro aspecto importante a ser considerado, por envolver o enriquecimento relativo em caulinita pela saída dos outros elementos originalmente associados na rocha intrusiva, é a retirada do ferro do sistema, processo este comandado pela presença da matéria orgânica, preservada na forma de turfeiras de gramíneas, comuns naquela regiâo da Serra do Espinhaço. Considera-se que a remobilização do ferro pode relacionar-se com a redução do $\mathrm{Fe}^{3+}$ para $\mathrm{Fe}^{2+}$, em funçấo do rebaixamento do potencial de "redox" para valores menores que zero, como conseqüência do acúmulo de matéria orgânica ao longo da antiga depressáo linear representada pelo dique. 


\section{CONCLUSŌES}

a. Dados morfológicos obtidos por MEV, associados a observações de campo, indicam, para a presente ocorrência de caulinita, uma origem tanto a partir da precipitaçāo de cátions presentes em águas meteóricas contendo sillica e alumínio originando os agregados euédricos observados, como também pela alteração de minerais alumino-silicáticos presentes na rocha original, formando as massas floculares anédricas de caulinita.

b. A remobilizaçăo do ferro da rocha intrusiva pode relacionar-se com sua reduçăo pelo rebaixamento do potencial de "redox" local, conseqüente da presença de matéria orgânica. A retirada do excesso da sílica pode ocorrer em clima quente e pH alcalino associados à existência de boa drenagem local. Processos mais amplos de concentração de alumínio, aliados à retirada mais efetiva de silica, ferro, potássio, etc. em rochas básicas alteradas, tem sido descrito no Espinhaço Meridional (ocorrências de bauxita mencionadas no texto).

c. Os contatos do caulim com as encaixantes sấo retilíneos ou marcados pela presença de veios de quartzo na interface. A única feição de alteração observada nas encaixantes foi a presença de intensa lateritização ferruginosa, inclusive com a formaçāo de canga. Por isto exclui-se uma origem hidrotermal para o corpo caulinizado em questão.

d. Observou-se grande semelhança mineralógica e química entre o corpo caulinizado da Serra do Espinhaço ora analisado e argilas cauliníticas da bacia terciária do Gandarela (SGARBI et al., 1991), estas seguramente de origem diagenética.

Sondagens a trado e perfis sísmicos de refração, a serem realizadas pelos autores no futuro, verificarăo a delimitação tridimensional do corpo caulinizado e suas relaçōes com a rocha original. Serăo ainda comparados os fatores da caulinização na área, com os corpos de bauxita também presentes na regiấo.

\section{AGRADECIMENTOS}

Os autores são gratos à Dra. Sylvia M.Couto e Célia R.F.Carvalho (PETROBRÁS/CENPES) pela confecção das análises por DRX, FRX e MEV e ao Dr. Carlos N.Khalil (PETROBRÁS/CENPES) pelas análises de CTC apresentadas. Análises por DRX também foram realizadas pelo Prof. Rui Z.L.Cançado e o acadêmico Cláudio A.C.Carneiro (Enga MINAS/UFMG), aos quais os autores agradecem. Os trabalhos de campo foram facilitados pela participação dos acadêmicos Gelson L.Fambrini e Marlei A.C.Chamani (IG/USP). O Centro de Geologia Eschwege em Diamantina (CGE/UFMG) gentilmente colocou à disposiçăo toda a infra-estrutura necessária à execuçăo dos trabalhos.

Os autores são gratos, ainda, à Pró-Reitoria de Pesquisa da UFMG (Projeto $\mathrm{n}^{\circ} 23072.024300 / 92-73$ ), que financiou os trabalhos de campo. 


\section{REFERÊNCIAS BIBLIOGRÁFICAS}

ANJOS, S.M.C.; CORDEIRO, C.R.; SOUZA, A.L.S. (1991) Análise por microscopia eletrônica de varredura em amostras de arenito e argila. Comunicaçäo Técnica Diger. Petrobrás/Cenpes, (60/91):1-8.

BLATT, H. (1988) Current problems in Diagenesis. In: SIMPÓSIO BRASILEIRO DE GEOQỨmICA, 3., Ouro Preto, 1988. Atas. Ouro Preto, SBGq. V.1, p.107-136.

GROSSI SAD, J.H. \& VAZ DE MELO, M.T. (1969) Recursos econઠ́micos do distrito de Serra, MG. Belo Horizonte. Geologia e Sondagens - Geosol/DNPM:1-179.

GUIMARĀES, D. (1933) Os anfibolitos da regiāo diamantífera do norte de Minas Gerais. Anais da Academia Brasileira de Ciências, 5(4):237-257.

JASMUND, K. (1979) X-ray fluorescence spectroscopy. In: OLPHEN, H.V. \& FRIPIAT, J.J. (eds.) Data handbook for clay materials and other non-metallic materials. London, Pergamon Press. p.155-161.

KHALIL, C.N. \& TEIXEIRA, L.C.F.L. (1990) Determinação de capacidade de troca cationnica de frações argila da Formação Sergi/Campo de Dom João. Comunicação Técnica Secres.Petrobrás/Cenpes, (15/90):1-8.

SCHÖLL, W.U. \& FOGAÇA, A.C.C. (1981) Projeto mapeamento geológico do Espinhaço Meridional, Quadrículas Guinda/Gouveia. Belo Horizonte, DNPM/UFMG. 44p.

SGARBI, G.N.C.; FANTINEL, L.M.; MASOTTI, F.S. (no prelo) Geologia dos sedimentos lacustres da bacia terciária do Gandarela, MG. In: SIMPÓSIO DE GEOLOGIA DE MINAS GERAIS, 6., Ouro Preto, 1991. Atas. Ouro Preto, SBG.

UHLEIN, A. (1982) Geologia e mineralogia de cromita e itabiritos na regiâo de Serra, MG. Brasília, 189p. (Tese de Mestrado - Instituto de Geociências/Universidade de Brasília).

WORTHINGTON, A.E.; GRANQUIST, W.T.; CLEMENCY, C.V. (1979) Cation exchange capacity. In: OLPHEN, H.V. \& FRIPIAT, J.J. (eds.) Data handbook for clay materials and other non-metallic materials. London, Pergamon Press. p.195-201. 